\title{
COMPARISON OF FREQUENCY OF ABNORMAL FETAL HEART RATE IN CONTINUOUS VERSUS DISCONTINUOUS USE OF OXYTOCIN INFUSION FOR AUGMENTATION OF LABOUR
}

\author{
Mehwish Anjum, Nilofar Mustafa*, Qurratulain Mushtaq*, Pakeza Aslam*, Saima Qamar*, Riffat Sarwar* \\ Combined Military Hospital Lahore/National University of Medical Sciences (NUMS) Pakistan, *CMH Lahore Medical College, Lahore/National University of \\ Medical Sciences (NUMS) Pakistan
}

\section{ABSTRACT}

Objective: To compare the frequency of abnormal fetal heart rate in continuous versus discontinuous use of oxytocin infusion for augmentation of labour.

Study Design: Comparative cross sectional study.

Place and Duration of Study: Department of Obstetrics and Gynaecology, Combined Military Hospital Lahore, from Feb to Aug 2018.

Methodology: After fulfilling the inclusion criteria, 76 patients were equally divided in two groups A and B. In both groups, at $3 \mathrm{~cm}$ dilatation, intravenous infusion of $5 \mathrm{IU}$ oxytocin in $500 \mathrm{cc}$ normal saline was initiated at infusion rate $3.3 \mathrm{mIU} / \mathrm{minute}$ Carditocography was initiated 10 minutes before infusion and then continued. An increment in infusion of $3.3 \mathrm{mIU} / \mathrm{minute}$ was done every 20 minutes till 4 to 5 contractions in 10 minutes were achieved. After this, no more increment was done. The maximum rate was 30mIU/minute. Once cervix was $5 \mathrm{~cm}$ dilated, infusion was continued in group A and discontinued in group B for 2 hours. Fetal heart rate was noted on cardiotocography from 20 minutes before initiation of infusion till 2 hours after $5 \mathrm{~cm}$.

Results: Age of the patients was $25.4 \pm 3.5$ years in group A and $26.1 \pm 2.4$ years in group B. Mean gestation age was $39.2 \pm 1.1$ weeks in group A and $38.6 \pm 1.3$ weeks in group B. Group A had significantly more abnormal fetal heart rate compared to group B $(p=0.016)$.

Conclusion: Discontinuous oxytocin infusion in labour showed significantly less abnormal fetal heart rate compared to continuous oxytocin infusion $(p=0.016)$.

Keywords: Fetal, Heart rate, Oxytocin, Uterine contraction.

This is an Open Access article distributed under the terms of the Creative Commons Attribution License (https://creativecommons.org/licenses/by-nc/4.0/), which permits unrestricted use, distribution, and reproduction in any medium, provided the original work is properly cited.

\section{INTRODUCTION}

Labor is a physiological process by which onset of uterine contractions cause dilatation and effacement of the cervix ${ }^{1}$. Onset of contractions is governed by a number of physiological changes including increase in prostaglandins, rise in oxytocin and expression of oxytocin receptors. These factors act on a cellular level causing increase in intracellular calcium which activates the enzyme myosin light chain kinase (MLCK) which stimulates interaction between myosin and actin. Subsequently cross-bridges form causing contraction.

An effective contraction lasts 60 seconds and intra uterine pressures reaches up to $50 \mathrm{mmHg}^{2}$. If the response is less than adequate, the process can be augmented by natural or synthetic agents, such as oxytocin and prostaglandins. The choice is governed by Bishop's score. If there is favorable Bishop's score, oxytocin augments contractions effectively by increasing the influx of calcium into the myometrial cells thus

Correspondence: Dr Qurratul Ain Mushtaq, Flat 145 F, Askari 5, Walton Airport Complex, Gulberg 3, Lahore Pakistan

Received: 25 Dec 2019; revised received: 30 Jun 2020; accepted: 07 Jul 2020 promoting stronger and more effective contractions.

The progression of labor depends on the three $\mathrm{P}^{\prime} \mathrm{s}$ : the passage (pelvis), the passenger (fetus), and the power (the contractions) ${ }^{2}$.

So apart from uterine contraction, cervical dilatation, descent and position of the fetus in the pelvis are assessed as well. Out of these, only uterine contraction is manageable with use of oxytocin.

Based on Friedman's recommendations, a cervical dilatation of $1-1.5 \mathrm{~cm}$ per hour between $4-10 \mathrm{~cm}$ of cervical dilatation has been expected as a standard 3,4 . Oxytocin has been used for treating protracted labour since long. Its use is generally preceded by amniotomy which causes an increased release of prostaglandins from the amniotic fluid which increase the uterine contractions in frequency and intensity ${ }^{5,6}$.

The concept of "active management of labor" was first published in 1984 by O'Driscoll. It meant adhering to a strict definition of onset of labor, early amniotomy and oxytocin if the progress of labor did not follow Friedman's curve ${ }^{7}$. In the following decade, active management of labor was widely implemented. 
The World Health Organization (WHO) has always considered oxytocin augmentation to be a major intervention that should have a valid indication . $^{8}$ Oxytocin causes fetal and maternal side effects. Common maternal side effects of oxytocin are headache, nausea, vomiting, hypotension, and reflex tachycardia and fetal side effect is fetal heart rate abnormalities ${ }^{9}$. The reason is that increased frequency of uterine contractions may interrupt blood flow to the fetus leading to poorer oxygenation of the fetal blood cells and eventually cause fetal asphyxia ${ }^{3}$. This is associated with variable and late decelerations.These complications increase the risk of caesarean section ${ }^{10}$. For this reason,fetal heart rate and uterine contractions must be monitored in all labours where augmentation is being done with oxytocin ${ }^{10}$.

There has been some interest of obstetricians in giving oxytocin as a discontinuous infusion as frequency of abnormal fetal heart rate has been shown to be much lower in women who receive discontinuous oxytocin regimen $(51 \%)$ compared to those who receive continuous infusion (20\%). Similarly uterine hyperstimulation is seen in $12 \%$ compared to $2 \%$ in discontinuous infusion group 1 . These effects of discontinuous infusion have not been associated with longer durations of labour.

Since fetal heart rate abnormalities are a frequent indication for caesarean sections, the use of discontinuous infusion may decrease the rate of caesrean section without lengthening the duration of labour ${ }^{10}$.

The rationale of our study was to see if discontinuous oxytocin use is associated with fewer heart rate abnormalities compared to continuous oxytocin which is generally given in the labour rooms and is associated with higher rates of intervention to ensure fetal well being.If less fetal heart rate abnormalities are associated with it, it can be advocated as a better way to augment labour.

\section{METHODOLOGY}

The comparative cross sectional study was conducted in department of Obstetrics and Gynaecology, Combined Military Hospital, Lahore, from February 2018 to August 2018.

Sample size of 76 (38 patients in group A and 38 patients in group B) was calculated with $80 \%$ power of test and $95 \%$ confidence interval while taking expected frequency of abnormal fetal heart rate to be $20 \%$ with discontinuous and $51 \%$ with continuous oxytocin infusion for augmentation of labor 13 (SOFTWARE USED
EPI INFO BY CDC ,USA). Non probability, convenience sampling technique was used. Patients included were primigravida presenting at gestational age of 3742 weeks as per dating scan, with ages in the range of 18-35 years undergoing labor augmentation with oxytocin, who signed written informed consent to participate in the study. Those excluded were with abnormal fetal cardiac activity (absent variability, bradycardia, decelerations) noted upon cardiotocography 10 minutes before starting oxytocin infusion, abnormal fetal lie (other than vertex presentation of fetus 20 minutes before active phase of labour as per obstetric ultrasound), suspected weight of fetus $>4 \mathrm{~kg}$ as per obstetric ultrasound before active phase of labour (ultrasound was performed by radiologist at $\mathrm{CMH}$ Lahore at time of admission), those taking anti-hypertensive therapy as per history and clinical record and those having preeclampsia (systolic blood pressure $>140 \mathrm{mmHg}$ ) as per history and clinical record.

After approval from ethics review committee of the hospital (IERB number 000384), patients who fulfilled the inclusion criteria were counselled and explained the details of the study. After informed consent, patients were divided into two groups:

- Group A: Continuous Oxytocin

- Group-B: Discontinuous oxytocin

A total of 76 cases were included in the study. Patients were divided in two groups (38 cases in each group). Group-A: continuous oxytocin infusion and Group-B: discontinuous oxytocin infusion. In both groups intravenous infusion was started at $3 \mathrm{~cm}$ dilatation with $5 \mathrm{IU}$ oxytocin in $500 \mathrm{cc}$ normal saline. Initial infusion rate was $3.3 \mathrm{mIU} /$ minute .An increment of 3.3 $\mathrm{mIU} /$ minute was done every 20 minutes. The objective was to achieve adequate contractions (up to 5 contractions 45 in 10 minutes). Once adequate contractions were achieved, no more increment was done in infusion rate. The maximum rate was $30 \mathrm{mIU} /$ minute.

Group A was given infusion for 2 hours after $5 \mathrm{~cm}$ cervix dilatation and in group B, infusion was discontinued for 2 hours after $5 \mathrm{~cm}$ cervix dilatation was achieved.

Fetal heart rate was noted in the patients from 10 minutes before start of oxytocin infusion with Cardiotocography (CTG) in both groups till $5 \mathrm{~cm}$ dilatation and further noted for 2 hours. Further management of labour and fetal heart rate monitoring was continued as indicated till delivery. 
All the data, including demographic data, were noted on a preformed proforma.

All the vaginal examinations were done by the same resident and all the CTG were performed on the same machine by the same resident to eliminate bias and confounding variables were controlled by exclusion.

Data wasanalyzed by SPSS-20. Numerical variables i-e maternal age and gestational age were presented by mean \pm SD.

Categorical variables i.e abnormal fetal heart rate was presented as frequency and percentage. Chi-square test was applied. The frequency of abnormal fetal heart rate was compared between two groups. The $p$ value $\leq 0.05$ was taken as significant.

Data were stratified for maternal age and gestational age to deal with effect modifiers. Post stratification chi-square was applied taking $p$-value of $<0.05$ statistically significant.

\section{RESULTS}

A total of 76 patients were included in the study. Mean age of the patients was $25.4 \pm 3.5$ and $26.1 \pm 2.4$ year in group-A and $\mathrm{B}$, respectively. In group-A mean gestation age was $39.2 \pm 1.1$ and in group-B $38.6 \pm 1.3$ week.

Abnormal fetal heart rate (decreased heart rate variability, early, late, variable deceleration) was found in $47.4 \%$ (18) in group A and $21 \%$ (8) in group B. Abnormal fetal rate was significantly more common in group-A as compared to group-B $(p=0.016)$ (table-I).

Stratification with regard to age and gestational age was also carried out (table-II \& III).

Table-I: Abnormal fetal heart rate.

\begin{tabular}{l|c|c}
$\begin{array}{l}\text { Abnormal } \\
\text { Retal Heart }\end{array}$ & $\begin{array}{c}\text { Group-A } \\
\text { (Continuous } \\
\text { Oxytocin), n (\%) }\end{array}$ & $\begin{array}{c}\text { Group-B } \\
\text { (Discontinuous } \\
\text { Oxytocin) n (\%) }\end{array}$ \\
\hline Yes & $18(47.4)$ & $8(21)$ \\
\hline No & $20(52.6)$ & $30(79)$ \\
\hline Total & $38(100)$ & $38(100)$ \\
\hline \multicolumn{2}{|c}{$p$-value $=0.016$} \\
\hline
\end{tabular}

\begin{tabular}{|c|c|c|c|c|}
\hline \multicolumn{5}{|c|}{ Table-II: Stratification for age. } \\
\hline \multirow{2}{*}{$\begin{array}{l}\text { Age } \\
\text { (Year) }\end{array}$} & \multirow[t]{2}{*}{ Group } & \multicolumn{2}{|c|}{$\begin{array}{l}\text { Abnormal Fetal Heart } \\
\text { Rage }\end{array}$} & \multirow{2}{*}{$\begin{array}{c}p- \\
\text { value }\end{array}$} \\
\hline & & Yes, n (\%) & No, $n(\%)$ & \\
\hline \multirow{2}{*}{$18-25$} & Group-A & $8(44.4)$ & $10(55.5)$ & \multirow{2}{*}{0.026} \\
\hline & Group-B & $1(7.6)$ & $12(92.3)$ & \\
\hline \multicolumn{2}{|l|}{ Total } & $9(29.03)$ & $22(70.9)$ & \\
\hline \multirow{2}{*}{$26-35$} & Group-A & $10(50)$ & $10(50)$ & \multirow{2}{*}{0.130} \\
\hline & Group-B & $7(28)$ & $18(72)$ & \\
\hline \multicolumn{2}{|l|}{ Total } & $17(37.7)$ & $28(62.2)$ & \\
\hline
\end{tabular}

Table-III: Stratification for gestational age.

\begin{tabular}{|c|c|c|c|c|}
\hline \multirow{2}{*}{$\begin{array}{l}\text { Gestational } \\
\text { Age (week) }\end{array}$} & \multirow{2}{*}{ Group } & \multicolumn{2}{|c|}{$\begin{array}{c}\text { Abnormal Fetal } \\
\text { Heart Rage }\end{array}$} & \multirow{2}{*}{$\begin{array}{c}p- \\
\text { value }\end{array}$} \\
\hline & & $\begin{array}{c}\text { Yes } \\
\text { n (\%) }\end{array}$ & $\begin{array}{c}\text { No } \\
\text { n (\%) }\end{array}$ & \\
\hline \multirow{2}{*}{$37-39$} & Group-A & $10(41.6)$ & $14(58.3)$ & \multirow{2}{*}{0.234} \\
\hline & Group-B & 7 (25.9) & $20(74)$ & \\
\hline \multicolumn{2}{|l|}{ Total } & $17(33.3)$ & $34(66.66)$ & \\
\hline \multirow{2}{*}{$39.1-42$} & Group-A & $8(57.1)$ & $6(42.8)$ & \multirow{2}{*}{0.013} \\
\hline & Group-B & $1(9)$ & $10(90.9)$ & \\
\hline \multicolumn{2}{|l|}{ Total } & $9(36)$ & $16(64)$ & \\
\hline
\end{tabular}

\section{DISCUSSION}

Oxytocin infusion used to manage slowly progressing labours has been associated with fetal heart rate abnormalities. These are a matter of concern as they lead to increased rate of caesarean sections. Researchers and clinicians are advocating judicial use of oxytocin. A few researchers are recommending discontinuous use of oxytocin to decrease these abnormalities. In our study, abnormal fetal heart rate was $47.4 \%$ in group with continuous oxytocin infusion and $21 \%$ in group with discontinued oxytocin infusion. This difference between two groups was statistically significant $(p=0.016)$. Our findings are comparable with the study of Bor et al who reported $51 \%$ fetal heart rate abnormalities with continuous oxytocin and $20 \%$ with discontinuous ${ }^{13}$. They suggested that discontinued use of oxytocin can improve labour outcome. However, another group of researchers have reported much less (40\%) rate of fetal heart rate abnormalities associated with oxytocin use. The rate, though less than what we found, is considerable ${ }^{14}$.

Boie et al found a significant rate of fetal heart rate abnormalities with continuous oxytocin infusion in systematic review of Cochrane database. Based on their review, they recommended that oxytocin infusion should be discontinued in active labour so that fetal heart rate abnormalities can be prevented (RR 0.15, $95 \%$ CI 0.05 to $0.46,3$ trials, 486 women, moderate-level certainty $)^{15}$.

Oxytocin associated CTG abnormalities were found in $60 \%$ cases by Helbeig et al in inter-institutional survey of oxytocin augmentation of labour ${ }^{16}$. These rates were much higher than those in our study however they included absent accelerations as a fetal heart rate abnormality whereas we only included decreased variability and early and late decelerations.

Oxytocin increases uterine activity and it leads to fetal hypoxemia which is depicted on CTG as fetal heart rate abnormalities. Hobson et al noted a $51 \%$ rate 
of fetal heart rate abnormalities with oxytocin when uterine contraction frequency was $>5$ in 10 minutes. This was different from our study where with $<5$ contractions, $47.4 \%$ fetal heart rate abnormalities were observed. Hobson et al observed that absent acceleration was the most common finding but in our study decreased fetal heart rate variability and early, late decelerations were observed in all $47.4 \%$ cases $^{17}$.

Oxytocin cause fetal heart rate abnormalities due to repeated interruption of blood flow to placental bed during prolong uterine contractions. For this reason, It should be considered only in patients with ripe cervix ${ }^{18}$. Both fetal heart and uterine contractions must be monitored continuously in all augmented labours where oxytocin is being used ${ }^{19,20}$. Since uterine hyperstimulation (when contractions are $>5$ in 10 minutes) increases the rate of abnormal fetal heart rate, discontinuing infusion once labour is established may be a useful prophylactic measure to prevent fetal heart rate abnormalities. However, there are not enough studies on when to stop oxytocin during labour ${ }^{21}$.

Most studies conducted so far on oxytocin use in labour have focused on rate of caesarean section and duration of labour. To the best of our knowledge very scarce date is available regarding frequency of abnormal fetal heart rate in labour augmented with continuous versus discontinuous oxytocin infusion.

The strength of our study is that it has gathered data from daily obstetric practice of busy labour room. It also focuses on fetal heart rate abnormalities whereas most studies before this have focused on duration of labour as primary outcome with use of oxytocin. This study will provide data to support limited oxytocin use in labour to decrease fetal heart rate abnormalities.

\section{CONCLUSION}

When labour was being augmented with oxytocin infusion, its discontinued use showed significantly less abnormal fetal heart rate as compared to continuous use.

\section{CONFLICT OF INTEREST}

This study has no conflict of interest to be declared by any author.

\section{REFERENCES}

1. Hanley GE, Munro S, Greyson D, Gross MM, Hundley V. Diagnosing onset of labor: a systematic review of definitions in the research literature. BMC Pregnancy Childbirth 2016; 16(2): 71.

2. Nishimura F, Mogami H, Moriuchi K, Chigusa Y. Mechanisms of thrombin-Induced myometrial contractions: Potential targets of progesterone. PLoS One 2020; 15(5): e0231944.
3. Mselle LT, Eustace L. Why do women assume a supine position when giving birth? The perceptions and experiences of postnatal mothers and nurse-midwives in Tanzania. BMC Pregnancy Childbirth 2020; 20(1): 36.

4. Oladapo OT, Souza JP, Fawole B, Mugerwa K, Perdoná G, Alves D, et al. Progression of the first stage of spontaneous labour: A prospective cohort study in two sub-Saharan African countries. PLoS Med 2018; 15(1): e1002492.

5. Oladapo OT, Diaz V, Bonet M, Abalos E, Thwin SS, Souza H, et al. Cervical dilatation patterns of 'low-risk' women with spontaneous labour and normal perinatal outcomes: a systematic review. Br J Obstet Gynaecol 2018; 125(8): 944-54.

6. Smyth RM, Markham C, Dowswell T. Amniotomy for shortening spontaneous labour. Cochrane Database Sys Rev 2013; (6): CD006167.

7. Ara B, Anwar A, Salam R. Comparison of mean duration of first and second stage of labour in term primigravida with and without phloroglucinol. Pak J Med Health Sci 2016; 10(3): 994-97.

8. Dalbye R, Bernitz S, Olsen IC, Zhang J, Eggebø TM, Rozsa D, et al. The labor progression study: the use of oxytocin augmentation during labor following Zhang's guideline and the WHO partograph in a cluster randomized trial. Acta Obstet Gynecol Scand 2019; 98(9): 1187-94.

9. Hidalgo-Lopezosa P, Hidalgo-Maestre M. Labor stimulation with oxytocin: effects on obstetrical and neonatal outcomes. Rev Lat Am Enfermagem 2016; 24(2): e2744.

10. Turner JM, Mitchell MD. The physiology of intrapar-tum fetal compromise at term. Am J Obstet Gynecol 2020; 222(1): 17-26.

11. Selin L, Wennerholm UB, Jonsson M, Dencker A, Wallin G, Wiberg-Itzel E, et al. High-dose versus low-dose of oxytocin for labour augmentation: a randomised controlled trial. Women Birth 2019; 32(4): 356-63.

12. Bostanc1 E, Kilicci C, Ozkaya E, Yayla CA. Continuous oxytocin versus intermittent oxytocin for induction of labor: a randomized study. J Matern Fetal Neonatal Med 2020; 33(4): 651-56.

13. Bor P, Ledertoug S, Boie S, Knoblauch NO, Stornes I. Continuation versus discontinuation of oxytocin infusion during the active phase of labour: a randomised controlled trial. Br J Obstet Gynaecol 2015; 123: 129-35.

14. Różańska-Walędziak A, Czajkowski K, Walędziak M, TeligaCzajkowska J. The Present Utility of the Oxytocin Challenge Test-A Single-Center Study. J Clin Med 2020; 9(1): 131.

15. Boie S, Glavind J, Velu AV, Mol BWJ, Uldbjerg N, de Graaf I, et al. Discontinuation of intravenous oxytocin in the active phase of induced labour. Cochrane database of Systematic Reviews 2018; 8(8): CD012274.

16. Helbig S, Petersen A, Sitter E, Daly D, Gross MM, et al. Interinstitutional variations in oxytocin augmentation during labour in German university hospitals: a national survey. BMC Pregnancy Childbirth 2019; 19(1): 238.

17. Hobson S, Abdelmalek M, Farine D. Update on uterine tachysystole. J Perinat Med 2019; 47(2): 152-60.

18. Institute for Safe Medication Practices. ISMP's list of high-alert medications. [Internet] 2008 Available from: www.ismp.org.

19. Chopra S, SenGupta SK, Jain V, Kumar P. Stopping oxytocin in active labor rather than continuing it until delivery: A viable option for the induction of labor. Oman Med J 2015; 30(5): 320-25.

20. American College of Obstetricians and Gynecologists: Induction of labor. Practice Bulletin 1999.

21. Daniel-Spiegel E, Weiner Z, Ben-Shlomo I, Shalev E. For how long should oxytocin be continued during induction of labour? Brit J Obstet Gynecol 2004; 111(4): 331-34. 